\title{
A genome-wide association study of limb bone length using a Large White $\times$ Minzhu intercross population
}

Long-Chao Zhang ${ }^{1 \dagger}, \mathrm{Na} \mathrm{Li}^{1,2+}{ }^{+}$Xin Liu ${ }^{1}$, Jing Liang ${ }^{1}$, Hua Yan ${ }^{1}$, Ke-Bin Zhao ${ }^{1}$, Lei Pu ${ }^{1}$, Hui-Bi Shi ${ }^{1}$, Yue-Bo Zhang ${ }^{1}$, Li-Gang Wang $^{1 *}$ and Li-Xian Wang ${ }^{1 *}$

\begin{abstract}
Background: In pig, limb bone length influences ham yield and body height to a great extent and has important economic implications for pig industry. In this study, an intercross population was constructed between the indigenous Chinese Minzhu pig breed and the western commercial Large White pig breed to examine the genetic basis for variation in limb bone length. The aim of this study was to detect potential genetic variants associated with porcine limb bone length.

Methods: A total of 571 F2 individuals from a Large White and Minzhu intercross population were genotyped using the Illumina PorcineSNP60K Beadchip, and phenotyped for femur length (FL), humerus length (HL), hipbone length (HIPL), scapula length (SL), tibia length (TL), and ulna length (UL). A genome-wide association study was performed by applying the previously reported approach of genome-wide rapid association using mixed model and regression. Statistical significance of the associations was based on Bonferroni-corrected $P$-values.

Results: A total of 39 significant SNPs were mapped to a $11.93 \mathrm{Mb}$ long region on pig chromosome 7 (SSC7). Linkage analysis of these significant SNPs revealed three haplotype blocks of $495 \mathrm{~kb}, 376 \mathrm{~kb}$ and $492 \mathrm{~kb}$, respectively, in the $11.93 \mathrm{Mb}$ region. Annotation based on the pig reference genome identified 15 genes that were located near or contained the significant SNPs in these linkage disequilibrium intervals. Conditioned analysis revealed that four SNPS, one on SSC2 and three on SSC4, showed significant associations with SL and HL, respectively.

Conclusions: Analysis of the 15 annotated genes that were identified in these three haplotype blocks indicated that HMGA1 and PPARD, which are expressed in limbs and influence chondrocyte cell growth and differentiation, could be considered as relevant biological candidates for limb bone length in pig, with potential applications in breeding programs. Our results may also be useful for the study of the mechanisms that underlie human limb length and body height.
\end{abstract}

\section{Background}

In humans and other mammalian species, individuals with greater limb length have greater body height. In humans, limb bone length is highly correlated with body height, with correlation coefficients reaching 0.60 to 0.88 [1-3]. Thus, analysis of genetic variants associated with limb bone length can contribute to our understanding of

\footnotetext{
*Correspondence: ligwang@126.com; iaswlx@263.net

${ }^{\dagger}$ Equal contributors

'Key Laboratory of Farm Animal Genetic Resources and Germplasm Innovation of Ministry of Agriculture, Institute of Animal Science, Chinese Academy of Agricultural Sciences, 100193 Beijing, China

Full list of author information is available at the end of the article
}

human height. The ease with which experimental designs can be conducted in domestic pig makes this species an important large animal model for human research as well as a major farm animal for meat production [4]. In pigs, limb length influences body height and thus, ham yield, to a great extent [5]. Porcine cured ham, such as Jinhua ham and Iberian ham, is one of the most popular and valuable meat products worldwide. However, in China, ham products are produced from indigenous pig breeds, most of which have smaller limb lengths than western commercial pig breeds such as Large White, Landrace, and Duroc [6]. Thus, understanding the genetic basis of the variation 
in limb length between the two types of pig breeds is of economic importance.

Based on the high-density panels of single nucleotide polymorphisms (SNP), genome-wide association studies (GWAS) have been developed to identify DNA variants associated with many complex diseases and traits in humans and animals $[7,8]$. Although quantitative trait loci (QTL) that affect limb bone length have been detected on pig chromosomes (SSC for Sus scrofa) SSC1, 2, 3, 4, 5, 7, $14,15,16,17$ and $X[9,10]$, to date, no GWAS has been carried out for this trait. The aim of this study was to detect potential genetic variants associated with limb bone length in a Large White $\times$ Minzhu intercross population using a GWAS and to identify candidate genes that are near these polymorphisms or that include them with major effects on this trait.

\section{Methods}

\section{Ethics statement}

All animals used in this study were treated according to the guidelines for experimental animals established by the Council of China. Animal experiments were approved by the Science Research Department of the Institute of Animal Science, Chinese Academy of Agricultural Sciences (Beijing, China).

\section{Population used and phenotype recording}

An intercross population was developed between a western commercial pig breed (long-limbed Large White) and a Chinese indigenous pig breed (short-limbed Minzhu), as described previously [11]. A total of 571 F2 animals (53 litters) were obtained from 36 F1 dams, which were mated to nine sires. All F2 piglets were weaned at 35 days of age and male pigs were castrated three days after birth. All F2 animals were slaughtered at $240 \pm 7$ days in 30 batches (slaughter groups).

After slaughter, both the forelimb and hind limb were removed from the left side of the carcass of the F2 animals. Six limb bones were dissected from these limbs and their lengths were measured using a caliper according to Mao et al. [9]. These included the femur (total length from the greater trochanter to the intercondyloid fossa), humerus (total length from the head to the trochlea), hipbone (length from the crista iliaca to the ramus inferior ossis pubis), scapula (the maximum straight line distance from the cavitas glenoidalis to the border of the scapular cartilage), tibia (length from the intercondylar eminence to the medial malleolus), and ulna (length from the olecranon process to the styloid process). A normal distribution test was applied for each trait using the univariate normal procedure in SAS software.

\section{Genotyping and quality control}

A total of 455 blood samples and 116 ear tissue samples were used for genomic DNA extraction using the saltingout method [12]. Genotyping was performed using Illumina PorcineSNP60 Genotyping BeadChip technology, which contained 62163 SNPs across the whole genome. Quality control procedures were performed for the $\mathrm{F} 2$ individuals using the GenABEL package [13] within the R statistical environment. Quality control filtering of SNPs was done as follows: SNPs that had a call rate below 90\%, or a minor allele frequency (MAF) below 3\%, or that were not in Hardy-Weinberg equilibrium (HWE) with a $P$-value below $10^{-6}$ were eliminated. The final dataset that passed the quality control procedure and was used in the analysis contained 48238 SNPs and 564 F2 individuals.

\section{Genome-wide association study}

The GWAS was performed by applying the genome-wide rapid association approach using mixed model and regression $[13,14]$, according to [11]. Sex, parity, and batch were selected as fixed effects for individuals and the litter effect was considered as a random effect. The DMU [15] and GenABEL software packages [13] in the R Language and Environment for Statistical Computing were used to analyze the data. A genome-wide significance threshold of 2.07E-08 (0.001/48238) was determined by the Bonferroni method, in which the conventional $P$-value was divided by the number of tests performed [16]. The most significant SNP was considered as a fixed effect and conditioned analysis was performed according to the GWAS procedure described above.

\section{Linkage disequilibrium analysis}

Linkage disequilibrium (LD) analysis was performed on the region that contained all SNPs that were significantly associated with limb bone length. The Haploview v4.1 program [17] was used to calculate linkage disequilibrium measures and to visualize haplotype blocks.

\section{Results}

\section{Phenotypes and correlations between traits}

Descriptive statistics including means, standard deviations, minimum and maximum lengths of limb bones of the F2 individuals are in Table 1. Mean values for femur length (FL), humerus length (HL), hipbone length (HIPL), scapula length (SL), tibia length (TL), and ulna length (UL) were equal to $21.64 \mathrm{~cm}, 18.72 \mathrm{~cm}, 25.46 \mathrm{~cm}, 17.37 \mathrm{~cm}, 19.38 \mathrm{~cm}$, and $21.04 \mathrm{~cm}$, respectively. The normal distribution test showed that not all traits followed a normal distribution. However, residuals, which were estimated in step 1 of the GWAS protocol as described previously [11], followed a normal distribution and were used as the dependent trait to 
Table 1 Descriptive statistics of the length of six limb bones

\begin{tabular}{lllll}
\hline Trait $^{\mathbf{1}}$ & Mean $(\mathbf{c m})$ & Std & Minimum $(\mathbf{c m})$ & Maximum $(\mathbf{c m})$ \\
\hline $\mathrm{SL}$ & 17.37 & 0.95 & 14.10 & 21.00 \\
$\mathrm{HL}$ & 18.72 & 1.32 & 15.00 & 22.80 \\
$\mathrm{UL}$ & 21.04 & 1.59 & 16.90 & 26.00 \\
$\mathrm{HIPL}$ & 25.46 & 2.14 & 15.10 & 31.50 \\
$\mathrm{FL}$ & 21.64 & 1.43 & 8.80 & 27.00 \\
$\mathrm{TL}$ & 19.38 & 1.48 & 15.80 & 27.70 \\
\hline
\end{tabular}

${ }^{1} \mathrm{SL}$, scapula length; $\mathrm{HL}$, humerus length; $\mathrm{UL}$, ulna length; HIPL, hipbone length; $\mathrm{FL}$, femur length; TL, tibia length.

test the associations using a single locus regression analysis (data not shown). The correlation coefficients between the traits are in Table 2 . All correlations were highly significant $(P<0.0001)$ and positive, and the coefficients ranged from 0.6211 to 0.7846 .

\section{Genome-wide association study}

After quality control, 48238 SNPs and 564 F2 individuals were used for the GWAS. The selected SNPs were distributed over 18 autosomes and the $\mathrm{X} / \mathrm{Y}$ chromosomes, as shown in [See Additional file 1: Table S1]. A threshold of 2.07E-08 (0.001/48238) was used in this study. Six traits were assessed; the resulting Manhattan plots and quantile-quantile (Q-Q) plots are in Figures 1 and 2, respectively. The Q-Q plot results showed an obvious deviation between the real and expected data and indicated that the association detected on pig chromosome SSC7 (SSC Sus scrofa) is statistically significant.

A total of 39 genome-wide significant SNPs were located in a $11.93 \mathrm{Mb}$ (Megabase) long region of the long arm of SSC7 (i.e. SSC7q) between 31.24 and $43.17 \mathrm{Mb}$. Of the 39 SNPs, 29, 35, 12, 6, 39, and 27 were significantly associated with FL, HL, HIPL, SL, TL, and UL, respectively [See Additional file 2: Table S2]. All significant SNPs were used for BLAST searches on the pig genome database (Build 10.2) and 14 of the SNPs were located within 13 annotated genes. All other SNPs were between 4327 and $137056 \mathrm{bp}$ away from the nearest known genes. The most significant SNP for each trait

Table 2 Phenotypic correlation coefficients between limb bone lengths

\begin{tabular}{llllll}
\hline Trait $^{1}$ & HL & UL & HIPL & FL & TL \\
\hline SL & 0.7358 & 0.7198 & 0.6373 & 0.7225 & 0.6211 \\
HL & & 0.7846 & 0.6654 & 0.7573 & 0.7540 \\
UL & & & 0.6621 & 0.7820 & 0.7350 \\
HIPL & & & & 0.6755 & 0.6233 \\
FL & & & & & 0.7236 \\
\hline
\end{tabular}

${ }^{1} \mathrm{SL}$, scapula length; $\mathrm{HL}$, humerus length; UL, ulna length; $H I P L$, hipbone length; $F L$, femur length; TL, tibia length. The correlation coefficients are listed in the upper triangle, and all $\mathrm{P}$ values of the correlation coefficients are lower than 0.0001 . was MARC0033464, which accounted for 47.93\%, $57.89 \%, 52.28 \%, 37.50 \%, 51.97 \%$, and $57.80 \%$ of the phenotypic variance for FL, HL, HIPL, SL, TL, and UL, respectively. In addition, 11 chromosome-wide significant $(P<6.16 \mathrm{E}-05)$ SNPs were identified in the distal region of SSC7q [See Additional file 3: Table S3].

\section{Conditioned analysis}

A conditioned analysis was performed using the most significant SNP, MARC0033464, as a fixed effect. The Manhattan and Q-Q plots obtained from the conditioned analysis are in [See Additional file 4: Figure S1 and Additional file 5: Figure S2], respectively. No significant SNP was detected on SSC7 after the conditioned analysis. However, four SNPs, one on SSC2 and three on SSC4, showed chromosome-wide associations with SL and HL, respectively [See Additional file 6: Table S4].

\section{Haplotype analysis}

Linkage analysis of the $11.93 \mathrm{Mb}$ region identified three haplotype blocks that ranged in size from $376 \mathrm{~kb}$ to $495 \mathrm{~kb}$ (Figure 3). Block1 495 kb long (between H3GA0020765 and ASGA0032526) and block2 $376 \mathrm{~kb}$ long (between H3GA0020824 and ASGA0032571) were both in complete LD $\left(r^{2}=1\right)$. Block1 contained the most significant SNP, MARC0033464, and six annotated genes, namely, glutamate receptor, metabotropic 4 (GRM4); high mobility group AT-hook 1 (HMGA1); nudix (nucleoside diphosphate linked moiety X)-type motif 3 (NUDT3); ribosomal protein S10 (RPS10); SAM pointed domain containing ETS transcription factor (SPDEF); and protein kinase $C$ and casein kinase substrate in neurons 1 (PACSIN1). Block2 contained five annotated genes, namely, chromosome 6 open reading frame 106 ortholog (C6ORF106), small nuclear ribonucleoprotein polypeptide C (SNRPC), UHRF1 binding protein 1 (UHRFBP1), TAF11 RNA polymerase II, TATA box binding protein (TBP)-associated factor (TAF11), and ankyrin repeat and sterile alpha motif domain containing 1A (ANKS1A). Block $3492 \mathrm{~kb}$ long (between H3GA0020849 and ASGA0032595) contained four annotated genes, namely, t-complex 11, testis-specific (TCP11); signal peptide, CUB domain, EGF-like 3 (SCUE3); peroxisome proliferator-activated receptor delta (PPARD); and FK506 binding protein 5 (FKBP5).

\section{Discussion}

We performed a GWAS for six porcine limb bone lengths and identified significant SNPs on the long arm of SSC7 between 31.24 and 43.17 Mb. A single QTL can influence multiple traits [4]. All significant SNPs were clustered in the same region, and the high correlation (0.62 to 0.78 ) among the six traits suggested that a QTL with a pleiotropic effect on limb bone lengths was located in the $11.93 \mathrm{Mb}$ region identified on SSC7q. 


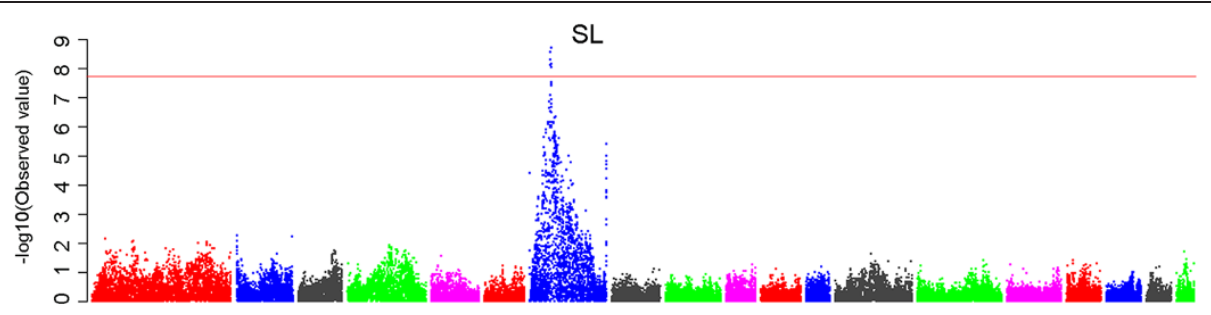

$\mathrm{HL}$

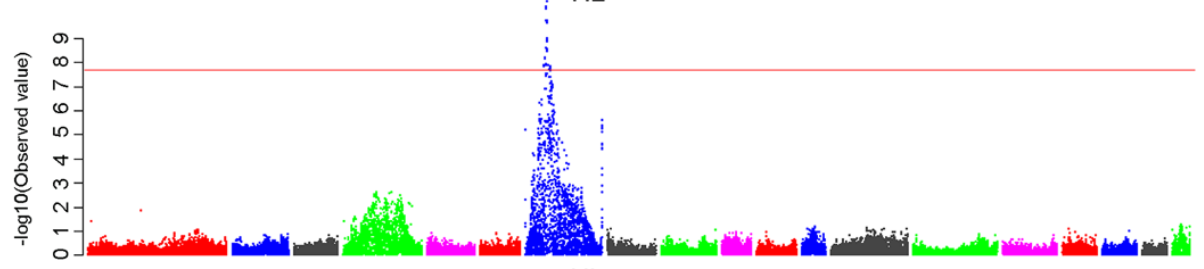

UL

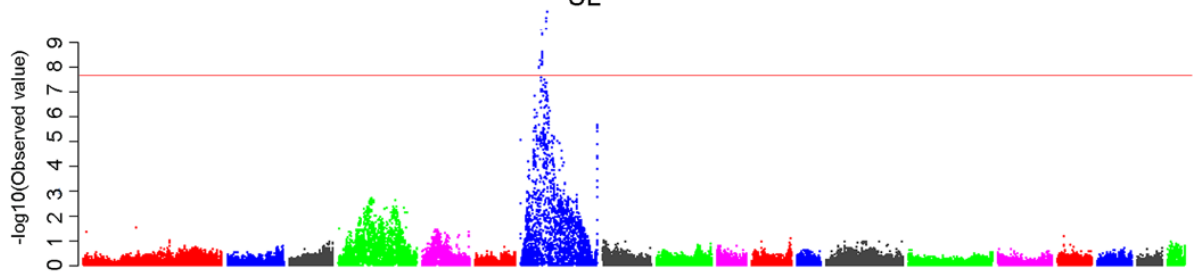

HIPL

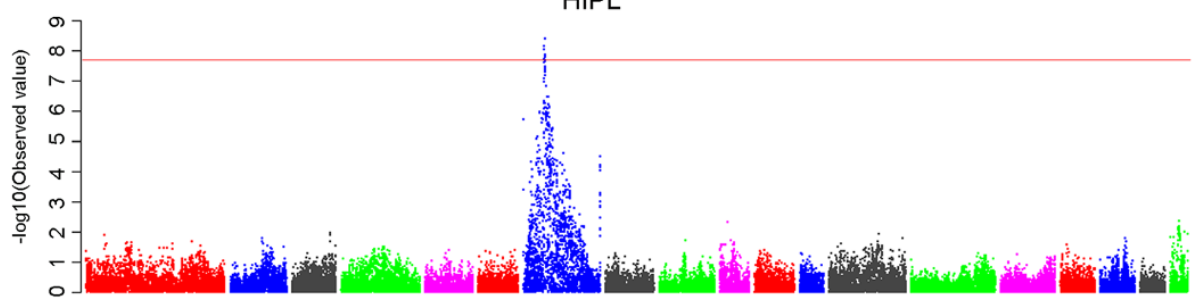

$\mathrm{FL}$

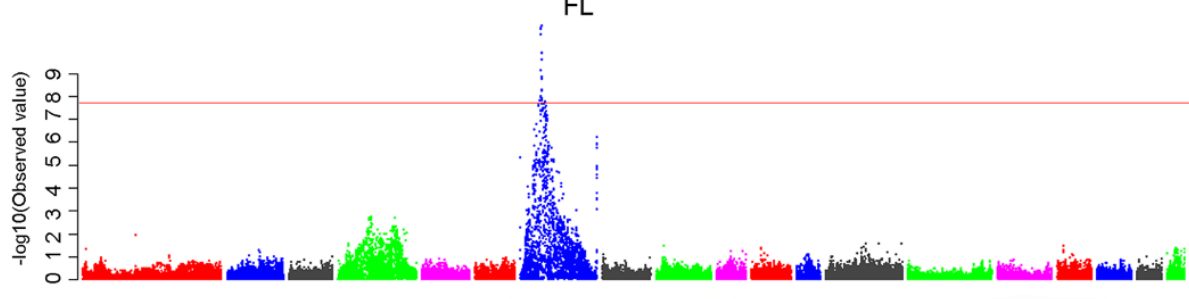

TL

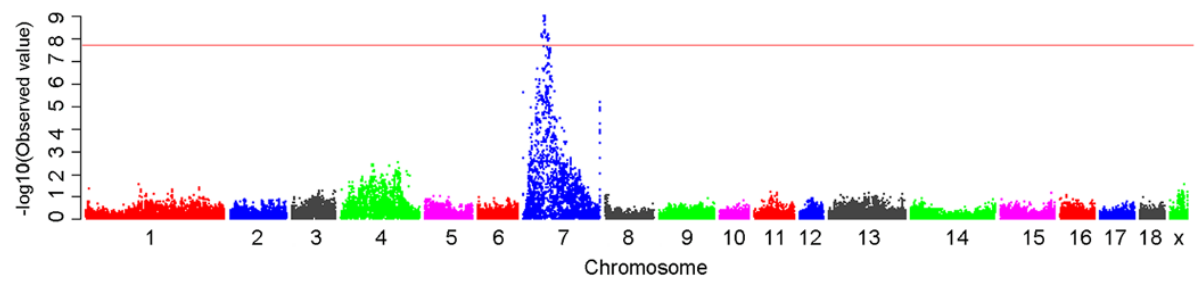

Figure 1 Manhattan plots of genome-wide association study with lengths of six limb bones. Chromosomes $1-18, X$ and $Y$ are shown in different colors. The red horizontal line indicates the genome-wide significance level (- $\left.\log _{10}(2.07 \mathrm{E}-08)\right)$.

To our knowledge, this is the first time that a genome-wide association of SNPs with HIPL is reported in pigs. These SNPs, which were also associated with the five other traits (FL, HL, SL, TL, and UL), were located within known QTL regions. Previously, a 108.89 Mb region (between 12.19 and
121.08 Mb) on SSC7 was reported to harbor a QTL that influenced limb bone length [9]. Our results narrow down this region to $11.93 \mathrm{Mb}$.

The additional significant SNPs found at the distal end of the SSC7q may result from the large linkage disequilibrium 


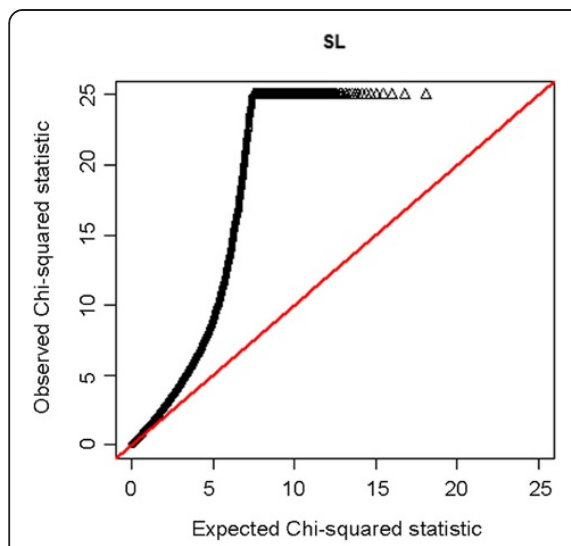

HIPL

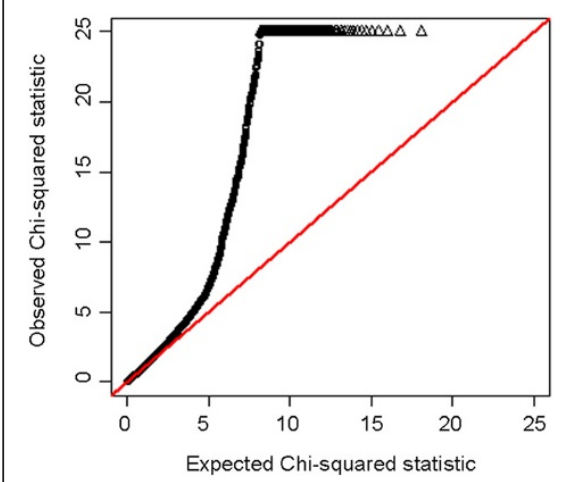

HL

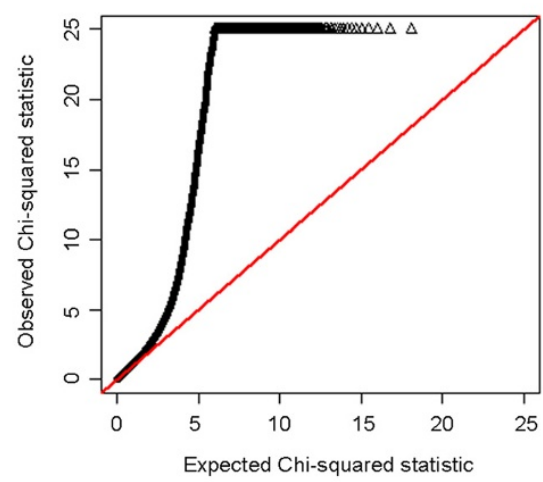

FL

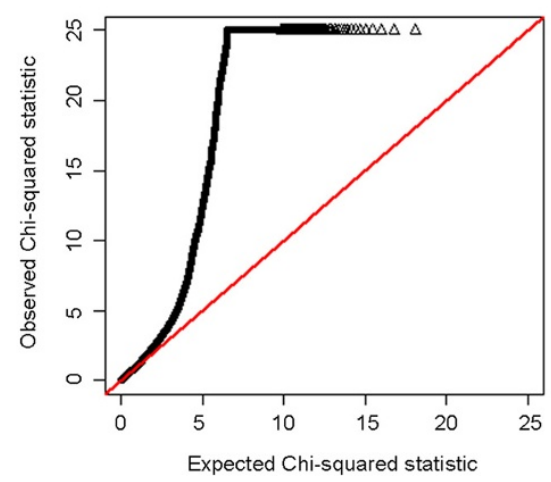

UL

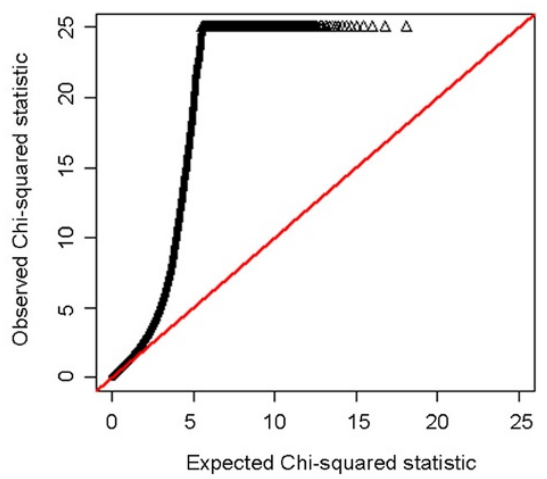

$\mathrm{TL}$

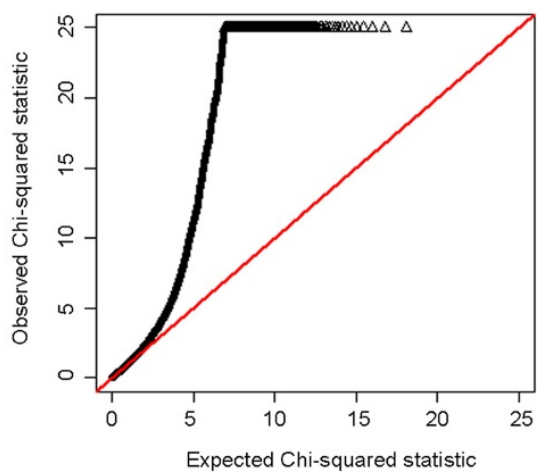

Figure 2 Quantile-quantile (Q-Q) plots. Results are shown in black. SNPs for which the test statistic exceeds 25 are represented by triangles.

that exists in the F2 design population [18]. Although the GWAS based on an F2 population design effectively narrowed down the QTL region, the large linkage disequilibrium present in this population is a limitation that can result in a larger linkage region than that observed using natural populations in livestock [19] or humans [20]. Linkage disequilibrium analysis was performed using all 233 chromosome-wide significant
SNPs. The fact that the SNPs at the distal end of SSC7q and other significant SNPs were not in LD [See Additional file 7: Figure S3] indicates that there was no obvious error in the genome assembly and the second peak in this region might be caused by a second QTL.

To overcome the above limitation, post-GWAS analysis often includes haplotype analysis, which is a

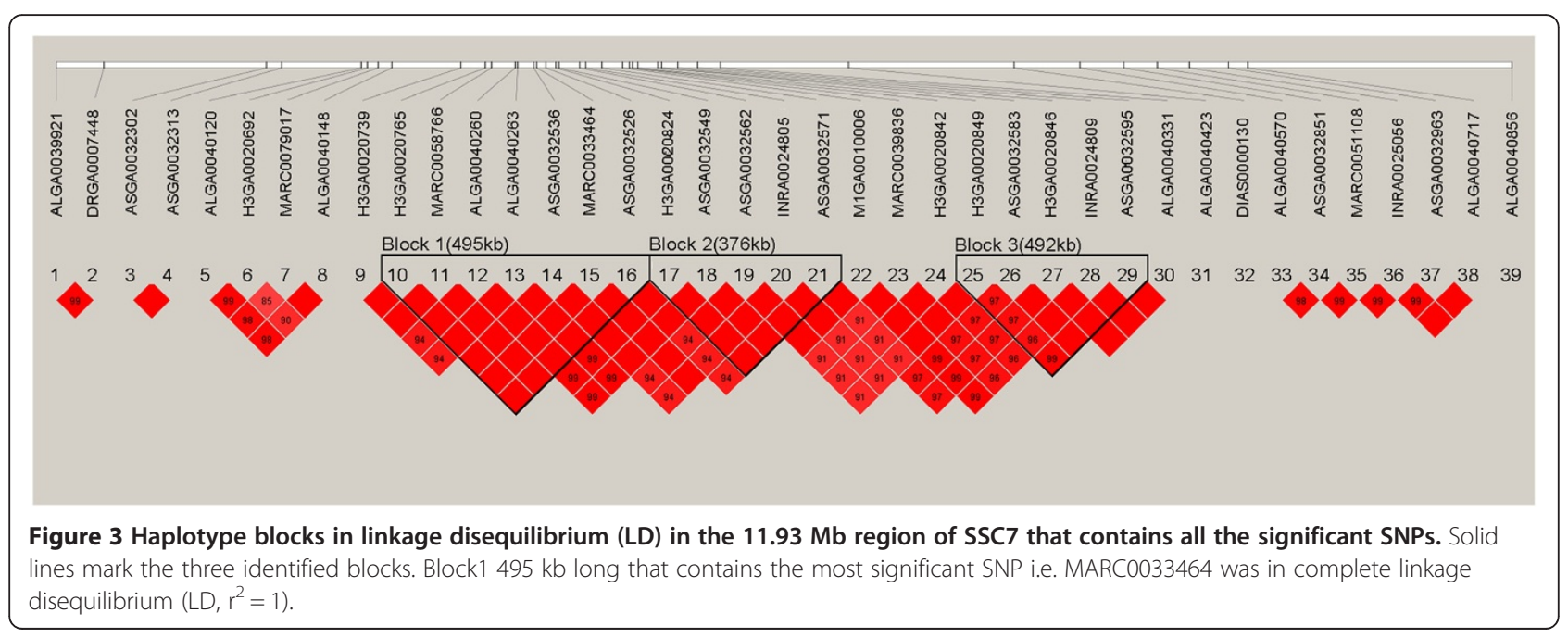


reliable method to identify the minimum segment that contains the causal gene [8]. Three haplotype blocks, respectively $376 \mathrm{~kb}, 492 \mathrm{~kb}$, and $495 \mathrm{~kb}$ long, were detected. Fifteen annotated genes were near or contained the significant SNPs of these three haplotype blocks. According to the mouse gene expression data in MGI (http://www.informatics.jax.org/), the genes GRM4, HMGA1, RPS10, SPDEF, SCUBE3, PPARD and FKBP5 are expressed in mouse limbs. However, GRM4, RPS10, $S P D E F$, SCUBE3, and FKBP5 are, respectively, involved in the regulation of neural stem cell differentiation [21], mediation of mammary luminal epithelial lineage-specific gene expression [22], association with diamond-Blackfan anemia [23], regulation of early lung cancer angiogenesis and metastatic progression [24], and regulation of the immunosuppressive function of myeloid-derived suppressor cells [25]. None of these genes have been reported to be associated with bone growth and, thus, cannot be considered as good candidates for limb bone length. The remaining genes, HMGA1 and PPARD, are involved in chondrocyte cell growth and differentiation. HMGA1 is ubiquitous in all cells of higher eukaryotes [26] and is known to have a biological role in cell growth and differentiation [27]. Silencing HMGA1 expression in invasive, aggressive cancer cells dramatically arrests cell growth and blocks their oncogenic properties, including proliferation, migration, invasion, and orthotopic tumorigenesis [28]. It was also shown that in vitro culture of porcine chondrocytes in the presence of HMGA1 increased their proliferation, which suggests that it could be a promising approach to enhance cartilage tissue repair and growth [29]. Furthermore, HMGA1 influences the expression of insulin growth factor-binding protein (IGFBP) and thus acts as a modulator of insulin-like growth factor I (IGF-I) activity [30], a gene which has been reported to be involved in bone growth, tibia length, body height, and body size in both humans and animals [31-35]. In addition, human GWAS have suggested that HMGA1 may be a good candidate for anthropometric traits. In Western European populations, GWAS revealed that SNP rs6918981 that is located near the HMGA1 gene contributed to height variation $\left(P<10^{-7}\right)$ [36]. Moreover, another SNP (rs1776897) located within the HMGA1 gene has been reported to have genome-wide associations with human height $(P=1.6 \mathrm{E}-08)$ and hip axis length $(P=0.005)$ [37].

Regarding the PPARD gene, Duan et al. [38] reported that its activation can inhibit chondrocyte differentiation and growth in pigs. Several reports have identified a PPARD variant associated with limb bone length, which indicates that it could be a good candidate for human height. A GWAS that included 183727 individuals showed that the PPARD gene was associated with human height [39]. Another GWAS study on individuals of African ancestry showed that an SNP (rs9470004) that is located in PPARD was associated with adult height $(P=1.0 \mathrm{E}-11)$ [40]. Therefore, both HMGA1 and PPARD can be considered as good candidates for limb bone length and should be studied further.

\section{Conclusions}

As for the human studies described above, our GWAS on a pig population revealed that the HMGA1 and $P P A R D$ genes displayed significant association with porcine limb bone length. These results confirm that pig is an appropriate large animal model for human height and limb length research. We conclude that HMGA1 and PPARD are relevant biological candidates for limb bone length in pigs. Further analyses of these genes based on additional genetic, functional, and computational studies are expected to provide novel insights into the genetic mechanisms responsible for limb bone length in different pig breeds and also perhaps for human height.

\section{Additional files}

Additional file 1: Table S1. Distribution of SNPS after quality control and average distances between SNPs on each chromosome. After quality control, a total of 48238 SNPs and 564 F2 individuals were used for the GWAS. According to the genome information of sus scrofa Build 10.2, the selected SNPs were distributed over 18 autosomes and the $X$ chromosome.

Additional file 2: Table S2. Genome-wide significant SNPS on SSC7 associated with limb bone lengths. Thirty-nine SNPs that are contained in a $11.93 \mathrm{Mb}$ (between 133.96 and $134.68 \mathrm{Mb}$ ) region at the long arm of SSC7 (i.e. SSC7q) were significantly associated $(P<2.07 \mathrm{E}-08)$ with limb bone lengths.

Additional file 3: Table S3. Chromosome-wide significant SNPS with limb bone length in the distal region of SSC7. Eleven SNPs that are contained in a $0.72 \mathrm{Mb}$ (between 133.96 and $134.68 \mathrm{Mb}$ ) region at the distal end of SSC7q were significantly associated $(P<6.16 \mathrm{E}-05)$ with limb bone length.

Additional file 4: Figure S1. Manhattan plots obtained from the conditioned analysis. After conditioned analysis, no significant SNP was detected on SSC7. However, four SNPS, one on SSC2 and three on SSC4, showed chromosome-wide associations with $\mathrm{SL}$ and $\mathrm{HL}$, respectively. The Manhattan plots are shown for CW, HTW and LUW and chromosome-wide significant SNPs for $\mathrm{CL}, \mathrm{FW}$ and $\mathrm{HW}$.

Additional file 5: Figure S2. Q-Q plots obtained from the conditioned analysis. After conditioned analysis, the results of the Q-Q plot showed an obvious deviation between the real and expected data and indicated that associations on SSC2 and SSC4 are statistically significant.

Additional file 6: Table S4. SNPs significantly associated with limb bone lengths after conditioned analysis. After conditioned analysis, four SNPS, one on SSC2 and three on SSC4, showed chromosome-wide associations with $\mathrm{SL}$ and $\mathrm{HL}$, respectively.

Additional file 7: Figure S3. Linkage disequilibrium analysis of 233 chromosome-wide significant SNPs. Using 233 chromosome-wide significant SNPs, linkage disequilibrium analysis was performed and identified 19 haplotype blocks (solid lines).

\section{Competing interests}

The authors declare that they have no competing interests. 


\section{Authors' contributions}

$L C Z, N L, L G W$ and LXW performed the statistical analysis and drafted the manuscript. $X L, L P, H B S, N L$ and $Y B Z$ collected the data. HY and KBZ participated in the discussions. ZL, LGW and XL wrote the manuscript. KBZ and $\mathrm{HY}$ conceived the study, and participated in its design and coordination and helped to draft the manuscript. All authors read and approved the final manuscript.

\section{Acknowledgements}

This research was supported by the Agricultural Science and Technology Innovation Program (ASTIP-IAS02), National Natural Science Foundation of China (31201781), National Key Technology R\&D Program of China (No.2011BAD28B01), earmarked fund for Modern Agro-industry Technology Research System, National Technology Program of China (No.2011ZX08006-003) and Chinese Academy of Agricultural Sciences Foundation (No.2014ZL006, No.2011cj-5, No.2012ZL069 and 2014ywf-yb-8).

\section{Author details}

'Key Laboratory of Farm Animal Genetic Resources and Germplasm Innovation of Ministry of Agriculture, Institute of Animal Science, Chinese Academy of Agricultural Sciences, 100193 Beijing, China. ${ }^{2}$ jilin Academy of Agricultural Sciences, 130033 Changchun, China.

Received: 28 January 2014 Accepted: 28 July 2014

Published online: 04 November 2014

\section{References}

1. Madden AM, Tsikoura T, Stott DJ: The estimation of body height from ulna length in healthy adults from different ethnic groups. $J$ Hum Nutr Diet 2012, 25:121-128.

2. Marinković N, Vilić JV: Correlation between the lengths of the long bones of the forearm and the fibula with body height in our population. Vojnosanit Pregl 2012, 69:394-398.

3. Neyestani TR, Dad-Khah M, Haidari H, Zowghi T, Maddah M, Nematy M, Aliabadi M: Determination of the actual height predictors in Iranian healthy children. Acta Med Iran 2011, 49:173-178.

4. Andersson L, Georges M: Domestic-animal genomics: deciphering the genetics of complex traits. Nat Rev Genet 2004, 5:202-212.

5. Hetzer HO, Hankins OG, King JX, Zeller JH: Relationship between certain body measurements and carcass characteristics in swine. J Anim Sci 1950, 9:37-47.

6. China National Commission of Animal Genetic Resource: Animal Genetic Resources in China: Pigs. Beijing: China Agriculture Press; 2011.

7. Hirschhorn JN, Daly MJ: Genome-wide association studies for common diseases and complex traits. Nat Rev Genet 2005, 6:95-108.

8. Xu X, Dong GX, Hu XS, Miao L, Zhang XL, Zhang DL, Yang HD, Zhang TY, Zou ZT, Zhang TT, Zhuang Y, Bhak J, Cho YS, Dai WT, Jiang TJ, Xie C, Li R, Luo SJ: The genetic basis of white tigers. Curr Biol 2013, 23:1031-1035.

9. Mao H, Guo Y, Yang G, Yang B, Ren J, Liu S, Ai H, Ma J, Brenig B, Huang L: A genome-wide scan for quantitative trait loci affecting limb bone lengths and areal bone mineral density of the distal femur in a White Duroc $x$ Erhualian F2 population. BMC Genet 2008, 9:63.

10. Andersson-Eklund L, Uhlhorn $H$, Lundeheim N, Dalin G, Andersson L: Mapping quantitative trait loci for principal components of bone measurements and osteochondrosis scores in a Wild Boar $\times$ Large White intercross. Genet Res 2000, 75:223-230.

11. Luo W, Cheng D, Chen S, Wang L, Li Y, Ma X, Song X, Liu X, Li W, Liang J, Yan H, Zhao K, Wang C, Wang L, Zhang L: Genome-wide association analysis of meat quality traits in a porcine Large White $\times$ Minzhu intercross population. Int J Biol Sci 2012, 8:580-595.

12. Miller SA, Dykes DD, Polesky HF: A simple salting out procedure for extracting DNA from human nucleated cells. Nucleic Acids Res 1988, 16:1215.

13. Aulchenko YS, de Koning DJ, Haley C: Genome-wide rapid association using mixed model and regression: a fast and simple method for genome-wide pedigree-based quantitative trait loci association analysis. Genetics 2007, 177:577-585.

14. Amin N, van Duijn CM, Aulchenko YS: A genomic background based method for association analysis in related individuals. PLOS ONE 2007 2:e1274.
15. Madsen P, Sorensen P, Su G, Damgaard LH, Thomsen H, Labouriau R: DMU - a Package for Analyzing Multivariate Mixed Models. In Proceedings of the $8^{\text {th }}$ World Congress on Genetics Applied to Livestock Production: 13-18 August 2006. Belo Horizonte: CD communication 27-11; 2006.

16. Yang Q, Cui J, Chazaro I, Cupples LA, Demissie S: Power and type I error rate of false discovery rate approaches in genome-wide association studies. BMC Genet 2005, 6:S134.

17. Barrett JC, Fry B, Maller J, Daly MJ: HAPLOVIEW: analysis and visualization of LD and haplotype maps. Bioinformatics 2005, 21:263-265.

18. Zhao K, Aranzana MJ, Kim S, Lister C, Shindo C, Tang C, Toomajian C, Zheng H, Dean C, Marjoram P, Nordborg M: An Arabidopsis example of association mapping in structured samples. PLoS Genet 2007, 3:e4.

19. Jiang L, Liu J, Sun D, Ma P, Ding X, Yu Y, Zhang Q: Genome wide association studies for milk production traits in Chinese Holstein population. PLOS ONE 2010, 5:e13661.

20. Klein RJ, Zeiss C, Chew EY, Tsai JY, Sackler RS, Haynes C, Henning AK, SanGiovanni JP, Mane SM, Mayne ST, Bracken MB, Ferris FL, Ott J, Barnstable C, Hoh J: Complement factor $\mathrm{H}$ polymorphism in age-related macular degeneration. Science 2005, 308:385-389.

21. Saxe JP, Wu H, Kelly TK, Phelps ME, Sun YE, Kornblum HI, Huang J: A phenotypic small-molecule screen identifies an orphan ligand-receptor pair that regulates neural stem cell differentiation. Chem Biol 2007, 14:1019-1030

22. Buchwalter G, Hickey MM, Cromer A, Selfors LM, Gunawardane RN, Frishman J, Jeselsohn R, Lim E, Chi D, Fu X, Schiff R, Brown M, Brugge JS: PDEF promotes luminal differentiation and acts as a survival factor for ER-positive breast cancer cells. Cancer Cell 2013, 23:753-767.

23. Chae H, Park J, Lee S, Kim M, Kim Y, Lee JW, Chung NG, Cho B, Chul Jeong D, Kim J, Kim JR, Park G: Ribosomal protein mutations in Korean patients with Diamond-Blackfan anemia. Exp Mol Med 2014, 46:e88.

24. Chou CH, Cheng YF, Siow TY, Kumar A, Peck K, Chang C: SCUBE3 regulation of early lung cancer angiogenesis and metastatic progression. Clin Exp Metastasis 2013, 30:741-752.

25. Kim YS, Kim YJ, Lee JM, Kim EK, Park YJ, Choe SK, Ko HJ, Kang CY: Functional changes in myeloid-derived suppressor cells (MDSCs) during tumor growth: FKBP51 contributes to the regulation of the immunosuppressive function of MDSCs. J Immunol 2012, 188:4226-4234.

26. Cleynen I, Van de Ven WJ: The HMGA proteins: a myriad of functions (Review). Int J Oncol 2008, 32:289-305.

27. Melillo RM, Pierantoni GM, Scala S, Battista S, Fedele M, Stella A, De Biasio MC, Chiappetta G, Fidanza V, Condorelli G, Santoro M, Croce CM, Viglietto G, Fusco A: Critical role of the HMGI(Y) proteins in adipocytic cell growth and differentiation. Mol Cell Biol 2001, 21:2485-2495.

28. Shah SN, Cope L, Poh W, Belton A, Roy S, Talbot CC Jr, Sukumar S, Huso DL, Resar LM: HMGA1: a master regulator of tumor progression in triple-negative breast cancer cells. PLOS ONE 2013, 8:e63419.

29. Richter A, Hauschild G, Murua Escobar H, Nolte I, Bullerdiek J: Application of high-mobility-group-A proteins increases the proliferative activity of chondrocytes in vitro. Tissue Eng Part A 2009, 15:473-477.

30. Hristov A, Cope L, Di Cello F, Reyes MD, Singh M, Hillion JA, Belton A, Joseph B, Schuldenfrei A, lacobuzio-Donahue CA, Maitra A, Resar LM: HMGA1 correlates with advanced tumor grade and decreased survival in pancreatic ductal adenocarcinoma. Mod Pathol 2010, 23:98-104.

31. Sutter NB, Bustamante CD, Chase K, Gray MM, Zhao K, Zhu L, Padhukasahasram B, Karlins E, Davis S, Jones PG, Quignon P, Johnson GS, Parker HG, Fretwell N, Mosher DS, Lawler DF, Satyaraj E, Nordborg M, Lark KG, Wayne RK, Ostrander EA: A single IGF1 allele is a major determinant of small size in dogs. Science 2007, 316:112-115.

32. Xu L, Nicholson P, Wang Q, Alén M, Cheng $\mathrm{S}$ : Bone and muscle development during puberty in girls: a seven-year longitudinal study. J Bone Miner Res 2009, 24:1693-1698.

33. Fitts JM, Klein RM, Powers CA: Tamoxifen regulation of bone growth and endocrine function in the ovariectomized rat: discrimination of responses involving estrogen receptor a/estrogen receptor $\beta, G$ protein-coupled estrogen receptor, or estrogen-related receptor $\gamma$ using fulvestrant (ICI 182780). J Pharmacol Exp Ther 2011, 338:246-254.

34. Xu L, Wang Q, Wang Q, Lyytikäinen A, Mikkola T, Völgyi E, Cheng S, Wiklund P, Munukka E, Nicholson P, Alén M, Cheng S: Concerted actions of insulin-like growth factor 1 , testosterone, and estradiol on peripubertal bone growth: a 7-year longitudinal study. J Bone Miner Res 2011, 26:2204-2211. 
35. Okada Y, Kamatani Y, Takahashi A, Matsuda K, Hosono N, Ohmiya H, Daigo Y, Yamamoto K, Kubo M, Nakamura Y, Kamatani N: A genome-wide association study in 19633 Japanese subjects identified LHX3-QSOX2 and IGF1 as adult height loci. Hum Mol Genet 2010, 19:2303-2312.

36. Cho YS, Go MJ, Kim YJ, Heo JY, Oh JH, Ban HJ, Yoon D, Lee MH, Kim DJ, Park M, Cha SH, Kim JW, Han BG, Min H, Ahn Y, Park MS, Han HR, Jang HY, Cho EY, Lee JE, Cho NH, Shin C, Park T, Park JW, Lee JK, Cardon L, Clarke G, McCarthy MI, Lee JY, Lee JK, et al: A large-scale genome-wide association study of Asian populations uncovers genetic factors influencing eight quantitative traits. Nat Genet 2009, 41:527-534.

37. Soranzo N, Rivadeneira F, Chinappen-Horsley U, Malkina I, Richards JB, Hammond N, Stolk L, Nica A, Inouye M, Hofman A, Stephens J, Wheeler E, Arp P, Gwilliam R, Jhamai PM, Potter S, Chaney A, Ghori MJ, Ravindrarajah R, Ermakov S, Estrada K, Pols HA, Williams FM, McArdle WL, van Meurs JB, Loos RJ, Dermitzakis ET, Ahmadi KR, Hart DJ, Ouwehand WH, et al: Meta-analysis of genome-wide scans for human adult stature identifies novel loci and associations with measures of skeletal frame size. PLoS Genet 2009, 5:e1000445.

38. Duan Y, Brenig B, Wu X, Ren J, Huang L: The G32E functional variant reduces activity of PPARD by nuclear export and post-translational modification in pigs. PLOS ONE 2013, 8:e75925.

39. Lango Allen H, Estrada K, Lettre G, Berndt SI, Weedon MN, Rivadeneira F, Willer CJ, Jackson AU, Vedantam S, Raychaudhuri S, Ferreira T, Wood AR, Weyant RJ, Segrè AV, Speliotes EK, Wheeler E, Soranzo N, Park JH, Yang J, Gudbjartsson D, Heard-Costa NL, Randall JC, Qi L, Vernon Smith A, Mägi R, Pastinen T, Liang L, Heid IM, Luan J, Thorleifsson G, et al: Hundreds of variants clustered in genomic loci and biological pathways affect human height. Nature 2010, 467:832-838.

40. N'Diaye A, Chen GK, Palmer CD, Ge B, Tayo B, Mathias RA, Ding J, Nalls MA, Adeyemo A, Adoue V, Ambrosone CB, Atwood L, Bandera EV, Becker LC, Berndt SI, Bernstein L, Blot WJ, Boerwinkle E, Britton A, Casey G, Chanock SJ, Demerath E, Deming SL, Diver WR, Fox C, Harris TB, Hernandez DG, Hu JJ, Ingles SA, John EM, et al: Identification, replication, and fine-mapping of loci associated with adult height in individuals of african ancestry. PLoS Genet 2011, 7:e1002298.

doi:10.1186/s12711-014-0056-6

Cite this article as: Zhang et al:: A genome-wide association study of limb bone length using a Large White $\times$ Minzhu intercross population. Genetics Selection Evolution 2014 46:56.

\section{Submit your next manuscript to BioMed Central and take full advantage of:}

- Convenient online submission

- Thorough peer review

- No space constraints or color figure charges

- Immediate publication on acceptance

- Inclusion in PubMed, CAS, Scopus and Google Scholar

- Research which is freely available for redistribution 